\title{
Transportation Network Planning for Urban Agglomerations
}

\author{
Xiangli Xie \\ College of Management and Economics, Tianjin University, Tianjin, China, 300072
}

Keywords: Urban agglomeration, Transport network, Logistics, Planning

\begin{abstract}
The development of urban agglomeration is inseparable from safe, efficient, convenient and economical transportation and logistics services. Promoting urban agglomerations integrated transport and logistics system construction, not only can significantly improve the ability to coordinate the development of Chinese cities agglomerations, but also stimulate domestic consumption and protect economic growth. Based on my learning experiences, this paper analyzes the characteristics of urban agglomeration traffic and supply demand, and then focus on the urban agglomerations comprehensive transportation system planning strategies. The research results contribute to a calm and objective urban agglomerations development plan of integrated transport and logistics system for the problems in the current situation of urban agglomerations traffic and freight transportation.
\end{abstract}

\section{Urban agglomerations and integrated transport system features}

Cultivating new economic growth pole has become an important strategy of urbanization with Chinese characteristics and promoting coordinated regional development. Currently, in China, in addition to the Yangtze River Delta, Pearl River Delta, Beijing, Tianjin and has developed into an international urban agglomerations with important influence, South Liaoning, Shandong Peninsula, the Yangtze River (Wuhan urban agglomeration), Tan, West Coast, Sichuan, Chongqing and other areas also entered the urban agglomerations development stage. Chinese contemporary urban agglomerations layout is shown in Fig. 1.

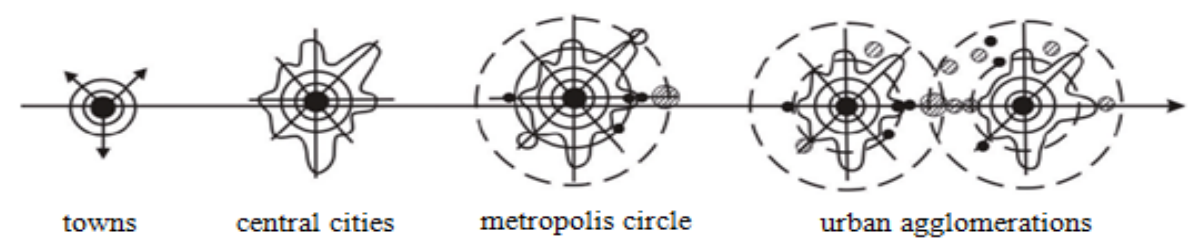

Fig. 1 Chinese contemporary urban agglomerations layout

Development of integrated transport and logistics system of urban agglomerations faces many challenges facing the center of the city, facing the group domain, facing the country and multi-level traffic and logistics demand globally, particularly in the formation of one or even several breakthroughs administrative divisions, commuting ring range up to tens of kilometers of large metropolitan core, which is an important feature of the current development of China's urban population.

\section{Demand characteristics analysis of urban agglomerations traffic and logistics}

Traffic and logistics demand analysis of urban agglomerations is based on the division of functions and industrial characteristics in various cities to analyze intrinsic motivation interconnected between them, the nature of passenger and freight transport demand. Urban Agglomeration can be divided into two types of metropolitan area and urban stretching area, and the corresponding traffic demand characteristics have also significant differences.

For the metropolitan area, it is generally divided into multiple spheres, although the number of specific spheres division is different, but summed up roughly divided into: the core area of the city center circle, the center of the city circle, circle and suburban outskirts circle. Each circle traffic and logistics characteristics are: Between the three spheres of the former commuter traffic is the main 
followed by public and commercial transportation. The first self-balancing degree circle is only 15 to 30 percent, existing significant heart traffic and logistics operation; the second circle peripheral zone with the first and second circle has obvious commuter features. Peak period trips per hour reaches 20 to 66 percent of day trips; Spheres suburban residential area to reach the first, second passenger about 20 to 55\% in the first, second circle of the total passenger traffic; Suburban circle contains more satellite towns, these suburban satellite towns should focus on production integration of the city, combined with the production live, livable industry and the supply chain, so that satellite towns perfect function self-contained. Therefore, the suburban commuter traffic circle most resolved satellite towns interior. Suburban traffic circle with other spheres is mainly for commercial traffic, followed by commuter traffic, but also including some tourist traffic. For metropolitan interlocking region level of urban agglomerations, its passenger and freight traffic characteristics and metropolitan area-level Urban Agglomeration is different. Metropolitan Interlocking Region can be divided into: 1 hour traffic circle, traffic circle 1 to 3 hours, 3 to 5 hours traffic circle and more than five hours traffic circle.

\section{Urban agglomeration comprehensive transportation system strategic planning}

Core metropolis circle - build people-oriented, bus-priority traffic system. Urban agglomerations core large metropolitan area as urban agglomeration socio-economic centers and major commuter traffic circle got a lot development with the acceleration of urbanization, core metropolis and surrounding neighborhood not only formed continuous urban areas, but also achieved a high degree of social and economic integration of the residents of employment, business, living, learning, and life will be extended to the entire range of activities metropolitan area, sometimes commuting radius is $30 \sim 50 \mathrm{~km}$ or more and the main passenger traffic corridor is up to several thousands or even millions people. Core metropolitan city transport system is focused on achieving the road network, rail network integration planning, and information networks, construction, operation and management, particularly in the metropolitan area to establish the dominant position of public transport, especially on the main passenger corridors fully reflect large capacity, fast, punctual, relatively comfortable role of rail transportation.

According to the growth stage modern urban agglomerations of "Towns - central cities metropolitan region - urban agglomerations", core metropolitan rail transport system in addition to strengthen internal contact center of the city itself, it should be extended to commuter traffic circle metropolitan area, strengthen ties with foreign central cities and urban agglomerations across the country to improve core radiation and to attract a large metropolitan area ability to form urban rail transport, urban area mass transit, passenger line (intercity rail) and a series of multi-level rail transport and logistics system.

The main intercity corridors - create a complex inter-city transport corridor structured and adapted to the different needs. Urban agglomerations core metropolis as the regional and national political, economic, transportation, culture, information centers, on the one hand, it produces the leading role for urban agglomerations, on the other hand, it cannot do without the support of urban agglomerations overall economic and social development. Other urban areas can be both energy and raw material base, it could be a modern manufacturing, modern agriculture and tourism and leisure base. New industrialization, new urbanization will further enhance regional industrial configuring rate, forming regional industry and accelerating the formation of a team regional common market. Rapid flow of integrated upstream and downstream industries, production factors, and optimal allocation of resources put a higher demand for regional passenger and freight transport, and it needs to upgrade intercity channel as soon as possible to suit various requirements, such as transport demand increased exponentially, significantly reducing transportation time, significantly improving transportation efficiency. To achieve regional resource sharing, dislocation competition, integration development needs to build relative adaptation water, land and integrated transport through the regional industry cluster development with the road, especially on the main intercity corridors, forming public, iron balanced development of intercity composite channel. 
Intercity complex transportation corridor laying parallel roads, railways, pipelines and other systems along the main intercity corridors, for the core metropolis as the center outward radiation of urban agglomerations main corridor, it needs laying parallel to the highway, intercity railway passenger line as the main characteristics of the public, iron-speed composite corridor. For the connecting corridors between urban agglomerations peripheral urban centers, generally laying highway, general-speed railway will be able to meet the transport needs, but for the Yangtze River Delta, Pearl River Delta and other world-class city, the center of the city between the perimeter sometimes needs emplaced city fast intercity rail connection.

The main port and station - built water, land and air transport hub which is fully functional with a modern integrated transfer facilities. Modern aviation hub. Major aviation hub as a key transportation facilities to strengthen domestic and international exchanges, upgrading the industrial structure is generally focused on the development of urban agglomeration, Pearl River Delta, Yangtze River Delta, Beijing, Tianjin and other cities group has geographical advantages to develop major international aviation hub portal or transit, etc., with the rapid development of trade, commerce, and tourism, building an international aviation hub airports and improving the regional airport core layout has become a major goal of China's urban population for an important air transport, modern high-end logistics development. For the Pearl River Delta, Yangtze River Delta, Beijing, Tianjin urban agglomerations, aviation hub needs to be connected all over the world and China's air gateway, to built the core aviation hub in the Asia Pacific region, for Midwest urban agglomerations, aviation hub should become a regional gateway for domestic and international air and built a national aviation transit hub.

Modern shipping center. Building shipping center has an important role in spurring economic development of the port city and the whole region. To develop waterway helps to alleviate the shortage of land for a long time on the channel capacity of coal, ore and other bulk cargo. Play waterway comparative advantage and meet the growing transportation needs of domestic and foreign trade to promote the development of various types of port industries to guide industrial division, Transference and accumulation. For the Yangtze River Delta, Pearl River Delta, Beijing, Tianjin and other coastal urban agglomerations, they should focus on the development of the global transport international shipping center; For Midwestern urban agglomerations, they should rely on the Yangtze golden waterway of the Yangtze River to build a regional shipping center, and strengthen the construction of the port and the backbone of regional core waterway.

Modern integrated logistics and transport hub. With the rapid development of urban rail transit, intercity rail, and a series of national passenger line, different levels of rail traffic, there has been a lot of railways, rail transportation is dominant mode of transportation of large-scale integration of various integrated transport hub. Building a modern large-scale integrated transport hub, not only help to improve the existing hub generally backward, poor image problem, but also helps the central city and outside the group to become the hub of convergence. Aggregation of a large number of urban rail transit and other public transportation facilities makes urban transport hub features more prominent, and the surrounding areas develop a strong TOD benefits.

Modern logistics park. Modern manufacturing, high-tech industry, all kinds of commerce are inseparable from the development of modern logistics services logistics park. The development of urban agglomeration logistics park should close around the various types of industrial parks, hi-tech parks, economic open zones and other industries supporting demand. Relying on airports, ports, rail station and other transportation hubs, for all levels in accordance with national, regional and urban, etc., lay outing national, regional, local logistics park or logistics centers to achieve a variety of logistics and transport and seamless service convergence. In general, the hub airports, and shipping centers need to be equipped radiation group domain large-scale integrated logistics park.

\section{Conclusion}

Currently, strengthening regional development and building a modern urban agglomeration have become the new key to China's new urbanization, industrialization and development. Strengthen research for urban agglomerations integrated transport and logistics system planning and related 
technologies, not only help to guide the rapid improvement of regional integrated transport issues, such as technological backwardness, lack of capacity, poor coordination, etc., but also helps to strengthen the ties between the regional social and economic in order to achieve urban agglomeration coordination and scientific development. In addition, it has a very important practical significance to shorten the development gap between eastern and western China and the development of urban-rural gap.

\section{References}

[1] Ahmed Elkafoury,Waled Dawoud, Abdelazim Negm, Mahmoud Bady, Mohamed H.Aly. FRAMEWORK FOR EVALUATING THE IMPACT OF URBAN TRANSPORTATION GASEOUS EMISSIONS ON GROUNDWATER QUALITY[A]. International Water Technology Association. Proceedings of Ground Water Flow and Contamination (GW) "A". International Water Technology Association:,2013:9.

[2] Ata M. Khan. Transportation Strategies for Sustainable Mega Cities. China Civil Engineering Society. Proceedings of the World Engineers' Convention 2004. China Civil Engineering Society:, 2004: 7.

\section{References}

[3] Y.D. Zhu., B. Wu, H.Y. Wang. Urban Agglomeration Comprehensive Transportation System Strategic Planning. Modern urban studies, 2001,04: 44-47.

[4] B.Z. Chen. L.F. Yang, Z.Q. Wang, Y. Gu. China Urban Agglomeration Comprehensive Transportation System Planning. Urban transport, 2010,01: 7-13.

[5] L.L. Wang. City Group Rapid Transit system planning study. Southwest Jiaotong University, 2008.

[6] Z.J. Liu. Urban Agglomeration transportation system planning studies. Chang'an University, 2011. 